\title{
CARACTERÍSTICAS DE LA NATURALEZA Y LOS PAISAJES DE CUBA
}

\author{
POR
}

EDUARDO SALINAS CHÁVEZ

\section{Caracteristicas geográficas generales de Cuba}

Situación geográfica. El archipiélago cubano constituye la porción más occidental del arco insular antillano e incluye la isla de Cuba, la mayor de las Antillas, la isla de la Juventud (ante isla de Pinos) y más de 4.000 pequeñas islas y cayos que rodean por el norte y el sur la isla principal, formando cuatro grupos insulares llamados: Los Colorados y Santa Isabel, Sabana y Camagüey, Jardines de la Reina y Los Canarreos. El área total emergida es de $110.993 \mathrm{~km}^{2}$, lo que representa el $89 \%$ del área total de las Antillas.

El archipiélago cubano, asentado en una plataforma submarina poco profunda de más de $67.000 \mathrm{~km}^{2}$, en forma de una llanura sumergida (Núñez Jiménez, 1982), se localiza en el Mar Caribe entre los continentes de Norteamérica y Sudamérica y cerca del Trópico de Cáncer, entre los $23^{\circ} 01^{\prime}$ y $19^{\circ} 49^{\prime}$ de latitud norte y los $74^{\circ} 07^{\prime}$ y $84^{\circ}$ $57^{\prime}$ de longitud oeste. Esta situación geográfica particular del archipiélago, junto con su compleja evolución geólogo-geomorfológica y su carácter insular se constituyen en factores determinantes de la diferenciación de la naturaleza cubana, como veremos más adelante.

Evolución geológica y relieve. El archipiélago cubano se encuentra ubicado, como apuntamos anteriormente, en el área del Caribe, una 
de las regiones más complejas de nuestro planeta desde el punto de vista geológico. Las principales características de su evolución geológica deben estudiarse tomando en consideración los aspectos siguientes:

La evolución del territorio, con complejas actividades tectónicas, magmáticas, metamórficas y volcánicas desde los períodos pre-jurásicos hasta el Eoceno. Como resultado del plegamiento, fracturamiento y cabalgamiento intenso, grandes volúmenes de rocas fueron expuestas especialmente en el Cretácico.

Transgresiones miocénicas generalizadas que condicionaron la disposición de gruesas capas de rocas carbonatadas y la formación de una extensa superficie plana que ayudó a unir los antiguos núcleos insulares formados durante los períodos Jurásico y Cretácico.

Nueva actividad tectónica del Plioceno, lo que conformó con sus diferentes ritmos y velocidades las principales morfoestructuras de Cuba y dividió los sistemas montañosos occidental, central y oriental de forma clara.

Los cambios en el nivel del mar ocurridos como consecuencia de los movimientos glacio-eustáticos que posibilitó la subdivisión del territorio en fragmentos aislados y su unión en diversas etapas. Se produjo además la confirmación de un importante sistema de terrazas marinas a lo largo de las costas del archipiélago cubano por la combinación de los movimientos glacio-eustáticos y los neotectónicos.

Estos fenómenos condicionan que el basamento geológico cubano presente un predominio de estructuras de tipo geosinclimal de «Arca de Islas», una geocronología particular de los procesos y elementos plicativos (lo que se manifiesta en el plano estructural actual) y una gan diversidad litológica (Mateo, J., 1988). El relieve del archipiélago cubano está compuesto por una mezcla de montañas y llanuras relacionadas con las diferentes etapas de su evolución geológica; el $60 \%$ del territorio está por debajo de los $200 \mathrm{~m}$ de altitud, el $25 \%$ entre 200 y $500 \mathrm{~m}$ y el $15 \%$ restante entre 500 y 2.000 m. En la Sierra Maestra, en la región oriental, se encuentra la mayor altura del país el Pico Real del Turquino, con 1974 m; en el occidente la altura máxima es el Pan de Guajaibón, con 692 m, y en la región central, el Pi- 
co San Juan, con 1.140 m. En general, los macizos montañosos se distribuyen como núcleos aislados que siguen la dirección principal de formación del arco insular de las Antillas Mayores, es decir, oeste-este.

El relieve cubano es en general joven y sus características principales vienen dada por los movimientos tectónicos neógeno-cuaternarios que transformaron de forma intensa las antiguas estructuras plegadas y enmascararon algunas de sus características principales bajo una espesa capa de rocas carbonatadas predominantemente calizas miocénicas. Se manifiesta en el territorio el predominio de la morfoescultura tropical caracterizada por una intensa alteración de las rocas, un rápido desarrollo del intemperismo químico, la fácil movilización de los materiales desintegrados (con la consecuente formación de espesas cortezas de intemperismo predominantemente ferralíticas) y una fuerte acción del escurrimiento concentrado en algunas épocas del año (Mateo, J., 1988). En más del 50 \% del territorio predominan los procesos kársticos en concordancia con el predominio de rocas carbonatadas, y las altas temperaturas y humedad.

Clima e hidrología. Las dimensiones de nuestro archipiélago, su carácter insular y la configuración de la Isla de Cuba (larga y estrecha) son las causas de las características climáticas mixtas y complejas del mismo. En este sentido se puede decir que en términos generales predominan las condiciones climáticas tropicales marítimas con una relativa uniformidad tanto espacial como temporal de las temperaturas por un lado y una marcada estacionalidad en el régimen de las precipitaciones en la mayoría del territorio por el otro. Localizada en el borde suroccidental del anticiclón subtropical del Atlántico Norte, Cuba está expuesta a la acción permanente de los vientos alisios con una dirección predominante del noreste. Las zonas costeras se ven sujetas además a la acción de las brisas durante todo el año, especialmente persistentes en la costa norte.

La variación anual de las temperaturas se nos muestra con un incremento en el período de mayo a octubre y una disminución en los meses de noviembre-abril. Las medidas mensuales y la media anual están por encima de los $20^{\circ}$, con una oscilación térmica anual entre 5 y $13^{\circ}$ (Lecha, L., y A. Florido, 1989). Las aguas marinas que rodean 
el archipiélago cubano se caracterizan por su uniformidad térmica y elevados valores de temperatura entre 24 y $29^{\circ}$ todo el año, lo que se constituye en un factor climático de especial importancia como regulador térmico y fuente de humedad en el archipiélago.

$\mathrm{El}$ régimen de las precipitaciones es muy complejo y diverso, oscilando entre 600 y $3.700 \mathrm{~mm}$, con un valor promedio anual de 1.383 $\mathrm{mm}$. La variación temporal es también característica para casi todo el territorio con excepción de la porción noreste de Cuba y algunas laderas a barlovento de los macizos montañosos más elevados donde incluso algunos autores hablan de la existencia de un clima del litoral de los alisios (González, E., y B. Lora, 1985). Esta variación temporal se expresa en un marcado carácter estacional y en la irregularidad de las precipitaciones de año en año.

Tres eventos meteorológicos de importancia afectan al clima de nuestro país: huracanes, frentes fríos y sures. Los huracanes tienen una frecuencia irregular, aunque sus efectos pueden ser devastadores para el país por los fuertes vientos y grandes volúmenes e intensidad de las precipitaciones. Los frentes fríos (noviembre-abril) causan una caída en las temperaturas y el incremento en las precipitaciones y velocidad de los vientos, a veces combinados con penetraciones del mar en la costa norte occidental predominantemente; los «sures» asociados con la época de mayor calentamiento y predominio de bajas presiones pueden ocasionar tormentas severas de corta duración.

Atendiendo a las condiciones climatológicas ya analizadas, el territorio de Cuba puede ser dividido en: Montañoso, con una humedad alta y estable, baja evaporación y temperaturas frescas. Llanuras interiores; con una humedad estacional y relativamente estable, alta evaporación y temperaturas cálidas. Llanuras costeras y cayos, con humedad insuficiente, evaporación muy alta y temperaturas muy cálidas. Para resumir las características principales de estos climas véase cuadro I.

El escurrimiento superficial en Cuba está relativamente limitado, como consecuencia de su configuración y constitución geológica. La divisoria de las aguas sigue el eje principal del país con dirección oeste-este, lo que origina dos grandes vertientes, norte y sur, por esta razón los ríos fluyen en una u otra dirección caracterizándose 
CUADRo I

CARACTERÍSTICAS PRINCIPALES DE LOS TIPOS CLIMÁTICOS DE CUBA

\begin{tabular}{|c|c|c|c|c|}
\hline & \multicolumn{3}{|c|}{ Tipos de clima } \\
\hline & & \multirow{2}{*}{\begin{tabular}{|c|} 
\\
$\begin{array}{c}\text { Montañoso con } \\
\text { humedecimiento } \\
\text { alto y estable, } \\
\text { baja evap. } \\
\text { y temp. frescas }\end{array}$ \\
$16-24$ \\
\end{tabular}} & \multirow[t]{2}{*}{\begin{tabular}{|c|} 
II \\
Llanuras y alturas \\
con humedecimiento \\
estacional, relat. \\
estable, alta evap. \\
y temperaturas \\
$23-28$ \\
\end{tabular}} & \multirow{2}{*}{\begin{tabular}{|c|} 
III \\
Llanuras y cayos \\
con humedad \\
insuficiente \\
e inestable, muy \\
alta evap. y temp. \\
$25-30$
\end{tabular}} \\
\hline \multirow{3}{*}{$\begin{array}{l}\text { Temperatura } \\
\text { Media del } \\
\text { aire }\left({ }^{\circ} \mathrm{C}\right)\end{array}$} & Anual & & & \\
\hline & $\begin{array}{l}\text { Enero } \\
\text { (Invierno) }\end{array}$ & $13-22$ & $21-26$ & $23-28$ \\
\hline & $\begin{array}{l}\text { Julio } \\
\text { (Verano) }\end{array}$ & $18-27$ & $26-30$ & $27-30$ \\
\hline \multirow{2}{*}{$\begin{array}{l}\text { Variación } \\
\text { diaria de la } \\
\text { temp. }\left({ }^{\circ} \mathrm{C}\right)\end{array}$} & Mínimas & $15-20$ & $15-25$ & $20-25$ \\
\hline & Máximas & $20-30$ & $30-35$ & $25-35$ \\
\hline \multicolumn{2}{|c|}{$\begin{array}{l}\text { Precipitación } \\
\text { Media Anual (mm) }\end{array}$} & $>1600$ & $1000-1600$ & $<1000$ \\
\hline \multicolumn{2}{|c|}{$\begin{array}{l}\text { Precipitación período } \\
\text { lluvioso (mayo-octubre) } \\
\text { en \% del total anual }\end{array}$} & $48-82$ & $50-86$ & $60-86$ \\
\hline \multicolumn{2}{|c|}{$\begin{array}{l}\text { Días con lluvia } \\
\geqslant 1 \mathrm{~mm} \text { (anual) }\end{array}$} & $>100$ & $70-100$ & $<80$ \\
\hline \multicolumn{2}{|l|}{$\begin{array}{l}\text { Insolación } \\
\text { (horas de sol) }\end{array}$} & $<2500$ & $2500-2900$ & 2900 \\
\hline \multicolumn{2}{|c|}{$\begin{array}{l}\text { Evaporación Media } \\
\text { Anual (mm) }\end{array}$} & $1200-1800$ & $1600-2300$ & $2200-2500$ \\
\hline \multicolumn{2}{|c|}{$\begin{array}{l}\text { Coeficiente de } \\
\text { humedecimiento medio } \\
\text { anual (K de Ivanov) }\end{array}$} & $1.10-2.50$ & $0.60-1.20$ & $0.30-0.70$ \\
\hline
\end{tabular}

Fuente: Nuevo Atlas Nacional de Cuba. 1989, Modificado

por cursos cortos, cuencas pequeñas y en general escaso caudal con una fuerte estacionalidad. Las aguas subterráneas juegan un papel importante en los recursos hidrológicos de Cuba, la amplia distribución de rocas carbonatadas, la alternancia de alturas y llanuras y la 
elevada infiltración en la época de lluvias condicionan la existencia de importantes volúmenes de aguas subterráneas de excelente calidad. Un elemento importante en la hidrografía cubana es la amplia distribución de los pantanos que ocupan más del $8 \%$ del área del país asociados principalmente a las costas bajas.

Existe en general una marcada variación estacional en los componentes del balance hídrico en el archipiélago Cuba, la cual se asocia además con la existencia de eventos catastróficos irregulares como son inundaciones, sequías, etc.

Suelos, flora y fauna. La distribución de los suelos en Cuba es muy compleja y está condicionada por la diferenciación geólogogeomorfológica y la diversidad en las condiciones de humedecimiento. La individualidad del clima favorece un intemperismo químico intenso y los procesos formadores de suelos, especialmente la ferralitización, así como un intenso lavado de los materiales solubles y la formación de arcillas. La roca madre juega un papel importante en la formación y diferenciación de los suelos, su influencia puede ser no sólo de forma directa, sino a través de las cortezas de intemperismo ampliamente distribuidas en todo el territorio. La correspondencia entre los procesos y tipos de suelos con la roca madre es muy importante, por ejemplo las rocas serpentiníticas forman en general suelos lateríticos, las margas; suelos húmicos carbonáticos; suelos pardos, etc.

La flora de Cuba es una de las flores insulares más rica del mundo con más de 7.000 especies de plantas, el endemismo puede exceder el $40 \%$ y más de 900 especies se encuentran en las diferentes categorías de vulnerabilidad o peligro de extinción. En cuanto a la fauna el archipiélago cuenta con cerca de 14.000 especies, de las cuales el $10 \%$ podría estar al borde de la desaparición. El inventario arroja la existencia de 54 especies de mamíferos ( $40 \%$ endémicas), 330 especies de aves ( 8 géneros, 22 especies y 32 subespecies son endémicas), 106 reptiles ( $81 \%$ endémicos), 42 anfibios (93\% endémicos), más de 1.700 moluscos ( $87 \%$ endémicos), 7.000 insectos y 1.200 arácnidos, así como una gran variedad de especies marinas entre las que cabe destacar la presencia de 59 especies de corales, 1.400 de moluscos y 1.100 de crustáceos.

$$
-206-
$$


Cuba presenta dos características importantes en su biota, que son las altas tasas de biodiversidad y endemismo, que han llevado a importantes organismos internacionales a patrocinar proyectos de investigación y colaboración en materia de protección ambiental. A medida que aumentan los estudios sobre nuestra biota aparecen elementos de mayor interés e importancia para la conservación a nivel mundial. Nuestro archipiélago, por ejemplo, presenta una diversidad de especies por $\mathrm{km}^{2} 22$ veces mayor que Nigeria, 36 veces mayor que la India y 42 veces mayor que Australia (Govorchin, R., 1995).

\section{Los paisajes de Cuba}

Hemos realizado hasta aquí el análisis de las características esenciales de los componentes de la naturaleza cubana por separado, pero conocemos que éstos interactúan entre sí para conformar sistemas integrales conocidos en la literatura científica como paisajes, geosistemas, complejos territoriales naturales, unidades ambientales, etc. Concebimos entonces al paisaje como «una unidad integral territorial, con una connotación espacial real, homogéna en sus diferentes partes, en un constante estado de intercambio de sustancia, energía e información, constituida por la asociación dialéctica de elementos, formados bajo la influencia de procesos naturales y las actividades humanas» (NC 93-06-101, Mateo, J., 1991, y Salinas, Ed., 1995).

Factores diferenciadores de los paisajes de Cuba. Los factores diferenciadores de los paisajes de Cuba, a saber, son:

- La insularidad; que se manifiesta en el predominio de los paisajes costeros, así como en una fuerte influencia marina en los componentes naturales; las peculiaridades de la flora y la fauna condicionadas por el aislamiento y la existencia de gran número de paisajes acuáticos.

- La complejidad del basamento geólogo-geomorfológico dado por el predominio de las estructuras geosinclinales, extensas áreas plegadas y elevadas, una compleja historia geológica y diversidad litológica que condicionan la asociación de llanuras, alturas y montañas y la combinación de diferentes tipos genéticos de relieve, lo que permite establecer que las diferencias morfoestructurales constituye la base de la diferenciación regional de nuestra naturaleza.

$$
-207-
$$


- La situación geográfica del archipiélago cubano en la porción norte de la faja tropical, es muy significativa por la influencia de los vientos alisios, las fuertes variaciones de la humedad asociadas con un régimen de precipitaciones muy complejo con valores anuales muy variables, la fuerte estacionalidad e irregularidades interanuales significativas y por último una fuerte influencia exposicional, no sólo en los macizos montañosos, sino también en la localización de las llanuras.

Características generales de los paisajes de Cuba. Los paisajes de Cuba presentan una gran diversidad en su organización interna, lo que se manifiesta en un gran número de unidades de paisaje (43 grupos, 84 especies y 99 subespecies) y una elevada complejidad condicionada por la gran cantidad de individuos existentes y su frecuente repetibilidad espacial. La diversidad y complejidad de los paisajes en Cuba aumenta con la altura, edad y complejidad del basamento geólogo-geomorfológico (Richling, A., y J. Mateo, 1991).

Predominan los paisajes de llanuras sobre los de alturas y montañas, existe una amplia distribución de los paisajes kársticos, las alturas y montañas bajas están mejor representadas que las montañas medias que sólo ocupan el $1 \%$ del territorio y además se puede asumir que la diferenciación altitudinal de los paisajes es más estrecha y compleja como consecuencia de la menor altura de las nubes (Figura 1).

El clima cálido y húmedo influye en los paisajes cubanos ocasionando una elevada producción anual de materia orgánica, lo que conlleva una intensa circulación biogeoquímica a lo largo del año, que unido a la fuerte circulación de agua, causa una alta movilización de elementos como: $\mathrm{Si}, \mathrm{Ca}, \mathrm{K}, \mathrm{Al}, \mathrm{Mg}$ y Fe entre otros.

En general los paisajes del archipiélago cubano presentan características comunes al resto de los paisajes insulares tropicales de los cuales forman parte, si bien por su tamaño y cercanía al continente norteamericano contienen algunos rasgos específicos de transición a los paisajes continentales. Las características principales de los paisajes insulares tropicales han sido resumidos en el cuadro número II. 


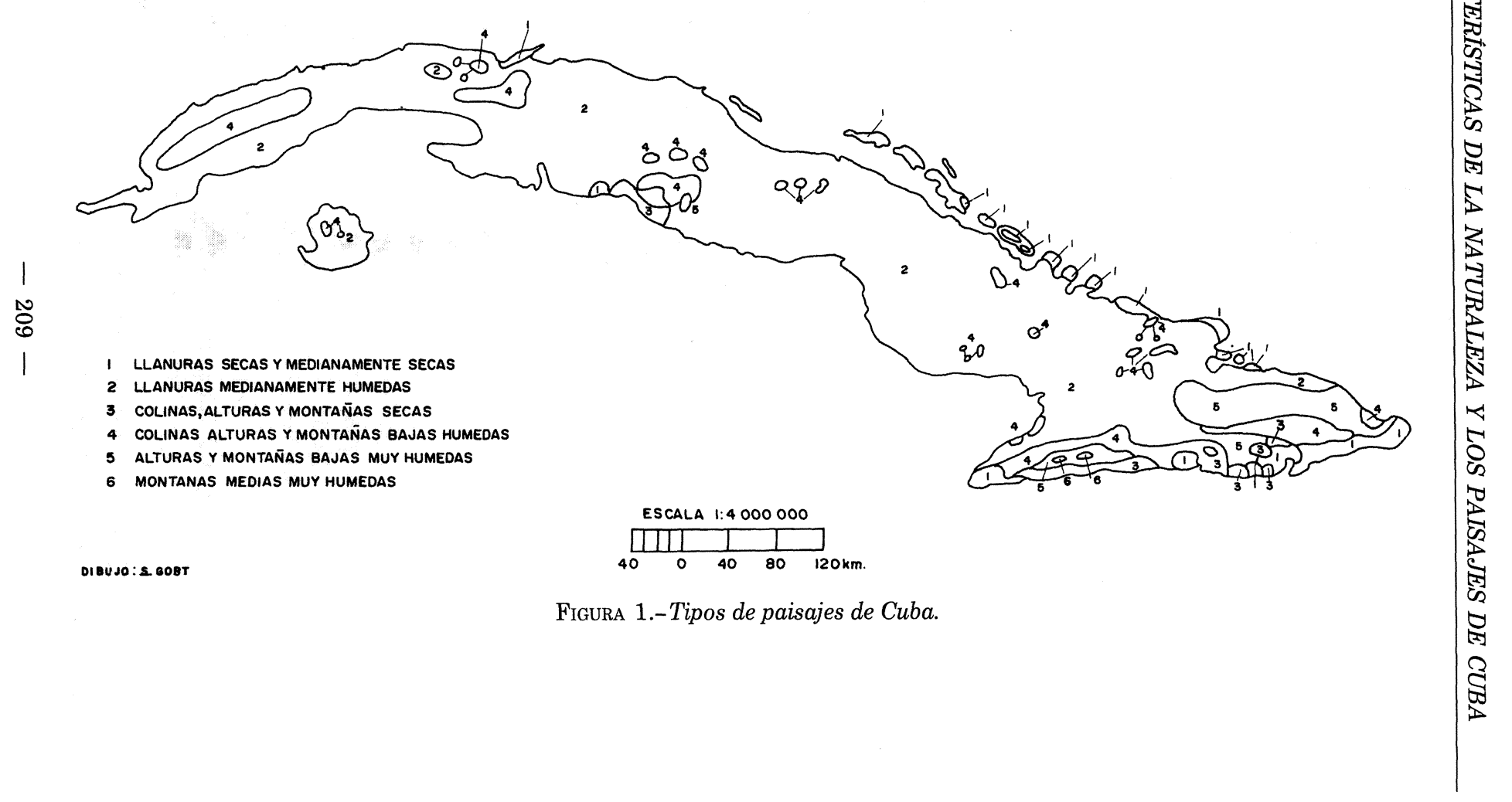


- Predominio de la variante oceánica en la diferenciación zonal.

- Zonalidad más simple que la existente en los continentes, pero más compleja que en los océanos.

- Zonalidad altitudinal diferente a la existente en los continentes, con un espectro altitudinal más estrecho y complejo como consecuencia de la menor altura de las nubes.

- Los factores diferenciadores de estos paisajes son: humedad del aire, velocidad de viento y nubosidad entre otros, los que provocan la especificidad de los paisajes insulares.

- Gran interacción entre el medio hídrico y la atmósfera lo que ocasiona fuertes intercambios biogeoquímicos.

- Existencia de paisajes en diferentes estadios de formación y de diferente edad.

- Los paisajes insulares se constituyen en geocomplejos autónomos por su aislamiento.

- Alto endemismo, empobrecimiento y vulnerabilidad de la biota.

FuENTE: Salinas, 1989

Paisajes de las llanuras. Estos paisajes se caracterizan por un mosaico en su composición litológica, condiciones climáticas relativamente homogéneas, altura absoluta inferior a $150 \mathrm{~m}$, poca variación de altura relativa, un régimen tectónico estable con poca intensidad de los movimientos neotectónicos, un intercambio de energía y sustancia horizontal relativamente menos intenso y el desarrollo de cortezas de intemperismo sobre las que encontramos suelos bien desarrollados (Iñíguez, L., y Mateo, J., 1980)

Atendiendo al régimen bioclimático, estos paisajes pueden dividirse en llanuras secas y medianamente secas, por un lado, y las llanuras medianamente húmedas, del otro. Las primeras ocupan pequeños territorios en áreas costeras y a sotavento de los sistemas montañosos, se caracterizan por las escasas precipitaciones, alta evaporación y prolongada estación seca lo que contribuye a la presencia de suelos poco desarrollados y bosque y matorrales secos xerófilos sustituidos por plantaciones de henequén y pastizales en muchos casos.

Las llanuras medianamente húmedas presentan una fuerte estacionalidad en el humedecimiento y se constituyen en el paisaje zonal

$$
-210-
$$


y por tanto más ampliamente distribuido en nuestro archipiélago con el predominio de suelos ferralíticos y pardos con carbonatos entre otros y bosques semideciduos con diferente grado de degradación y sustitución (véase Figura 2). Se incluyen en este tipo de paisaje: Llanuras cársicas con suelos ferralíticos y rendzinas con caña de azúcar, cultivos y bosques semideciduos. Llanuras denudativas y erosivo-denudativos sobre rocas variadas con caña de azúcar y pastos. Llanuras acumulativas arenosas y semiarenosas que circundan a algunos macizos montañosos con plantaciones de tabaco, cítricos, pastos y restos de pinares. Llanuras denudativas en rocas volcánicas y metamórficas ampliamente distribuidas en el país con suelos pardos y fuerte actividad agropecuaria en sustitución de bosques semideciduos. Llanuras aluviales, con un carácter moderadamente pantanoso asociadas con depósitos arcillosos y arenosos con suelos oscuros plásticos y otros con cultivo de arroz, hortalizas y restos de bosque semideciduo. Llanuras pantanosas con humedecimiento excesivo en turbas y fangos con suelos hidromórficos con bosques húmedos, herbazales y manglares.

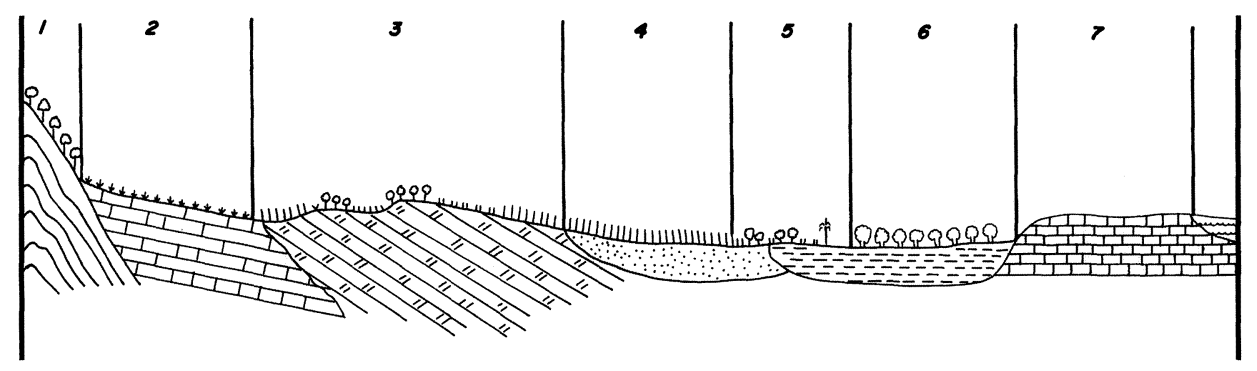

Figura 2.-Perfil físico-geográfico de la llanura septentrional de Villa Clara.

Paisajes de las alturas y montañas. Estos paisajes presentan una estructura más compleja que los de las llanuras como consecuencia de la combinación de la diferenciación vertical y horizontal, así como por una gran diversidad del basamento geólogo-geomorfológico, lo que se expresa en una serie de pisos altitudinales característicos (véase Figura 3). A pesar de no existir en el archipiélago grandes y elevados macizos montañosos, encontramos una fuerte influencia de la exposición a los rayos solares y a los vientos, inestabilidad tectóni-

$$
-211-
$$




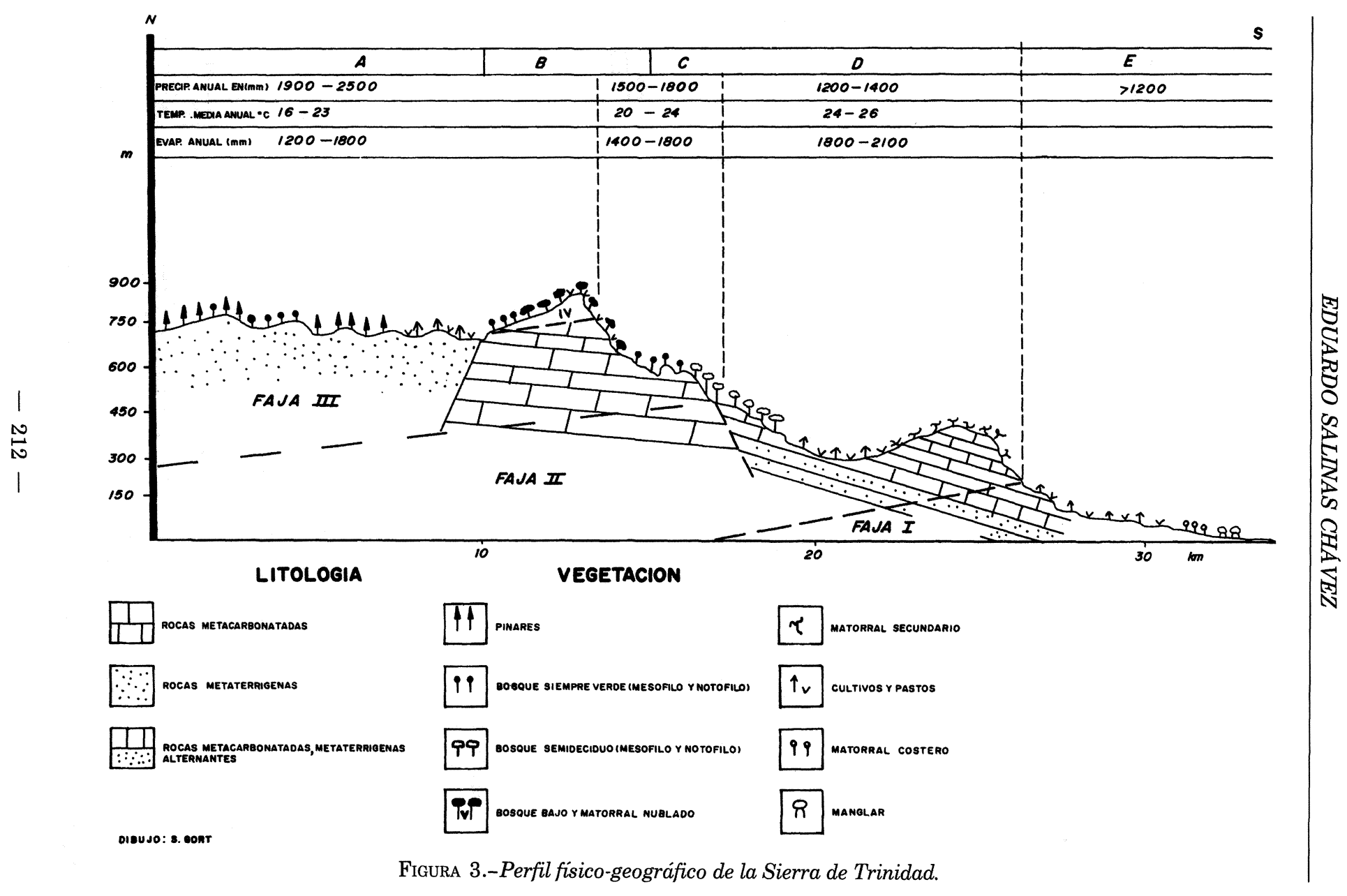


ca, fuertes procesos erosivos y amplia variedad litológica. Atendiendo a las condiciones bioclimáticas los paisajes montañosos de Cuba pueden dividirse en tres tipos: secos, húmedos y muy húmedos.

Las alturas y montañas secas, comprenden las colinas y alturas denudativo-kársticas y estructuro-denudativas formadas en rocas sedimentarias y volcánicas con suelos pardos con bosque seco y matorrales, así como las macropendientes meridionales de los macizos montañosos del centro y oriente de Cuba, erosivo-denudativas en rocas vulcanógeno-sedimentarias y metamórficas con suelos pardos y litosoles con herbazales y matorrales.

Las alturas y montañas húmedas, que incluyen: las depresiones intermontanas con suelos ferralíticos y pardos con cultivos, pastos y bosque siempre verde, las colinas y alturas denudativo-kársticas en rocas sedimentarias con suelos pardos, ferralíticos y litosoles con pastos, bosque semideciduo y vegetación de «mogotes», las colinas y alturas denudativas en rocas metamórficas, volcánicas y sedimentarias con suelos lateríticos, ferralíticos y pardos con pastos, matorrales y bosque semideciduo y, por último, las montañas bajas denudativas en rocas volcánicas, metamórficas y sedimentarias con suelos lateriticos, pardos y litosoles con bosque siempreverde y pinares.

Las alturas y montañas muy húmedas, incluyen las alturas en rocas sedimentarias y volcánicas con suelos ferralíticos, litosoles y pardos con bosque tropical húmedo, siempre-verde y plantaciones de café y cacao; las montañas bajas denudativas en rocas metamórficas y volcánicas con suelos ferralíticos, lateritas, pardos y litosoles con bosque tropical húmedo, matorrales, bosque nublado y plantaciones de café y cacao. Finalmente las montañas medias estructuro-denudativas en rocas volcánicas y metamórficas, con suelos pardos húmedos, ferralíticos y litosoles con matorrales y bosque nublado.

\section{La modificación humana de los paisajes}

El análisis histórico de las modificaciones humanas de la naturaleza de Cuba, está íntimamente relacionado con cinco siglos de total despreocupación por nuestros valores naturales y una explotación anárquica e irracional de los recursos naturales. Antes del descubri- 
miento los pobladores de Cuba habían provocado importantes modificaciones locales por la asimilación de pequeñas áreas para el desarrollo de una agricultura primitiva y las actividades de recolección, caza y pesca. Los aborígenes cubanos pertenecían a dos grandes grupos: recolectores, pescadores, cazadores no ceramistas y agricultores ceramistas. Arribaron a nuestro archipiélago en migraciones sucesivas, aproximadamente desde el año 2000 a. C., principalmente desde la región norte de Sudamérica a través de las Antillas menores y del valle del Mississippi. Se considera que en la época de mayor florecimiento a la llegada de los colonizadores españoles pudieron alcanzar una población de alrededor de 200.000 individuos distribuidos principalmente en la región oriental y central de Cuba (Tabio, E., y E. Rey, 1979). Esta primera etapa en la modificación de la naturaleza cubana puede considerarse como intensa muy localizada por lo que la mayor parte del archipiélago se caracterizaba a la llegada de los españoles por su alta naturalidad y más del $90 \%$ del territorio estaba cubierto de bosques (Iñiguez, L., 1983).

Con la fundación y desarrollo de las primeras villas en las primeras décadas del siglo XVI y especialmente después de la primera mitad de ese siglo comienza una segunda etapa en la modificación de nuestros paisajes que se extendió hasta fines del siglo XIX y que de forma general puede caracterizarse como intensiva de forma extensiva en todo nuestro territorio y muy intensa localmente. En esta etapa se produjo la repartición de casi todo el territorio nacional en propiedades rurales, en los primeros tiempos la ganadería se convirtió en la principal actividad económica de Cuba lo que condicionó el surgimiento del latifundio ganadero y la tala de extensas áreas de bosque para el desarrollo de la misma, conjuntamente con la extracción de maderas preciosas y la construcción de barcos.

En el siglo XVII comienza el auge de la industria azucarera que se combina con el desarrollo de otras actividades agrícolas especialmente el cultivo del tabaco, continúa el desarrollo ganadero y comienzan las explotaciones mineras. Se puede hablar en este período de una asimilación intensa de los paisajes de llanura especialmente en los alrededores de las florecientes villas como La Habana, Trinidad, Sancti Spíritus, Puerto Príncipe (hoy Camagüey), Nuevitas y Santiago de Cuba, entre otras. Esta etapa se caracterizó por la sustitución de la

$$
-214-
$$


mano de obra aborigen (algunos autores consideran desaparecieron alrededor de 1550) por esclavos africanos, traídos principalmente de la región del Golfo de Guinea, lo que se convirtió en un gran negocio y en uno de los genocidios más crueles que haya visto la humanidad (Pérez de la Riva, J., 1977).

El desarrollo intenso de la industria azucarera desde la segunda mitad del siglo svIII y especialmente en el siglo xIx provocaron una asimilación intensa en grandes áreas de nuestro país especialmente el occidente y centro. Se talaron extensos territorios para el aprovechamiento agrícola de las tierras y para la utilización de la madera como combustible en la producción del azúcar. En 1800, la población de la Isla se considera alcanzaba los 600.000 habitantes, de ellos una parte importante eran negros esclavos (Guerra, R., 1975). A fines del siglo XIX se considera que aún el $56 \%$ de nuestro país estaba cubierto de bosques los que se extendían principalmente en las áreas montañosas de la porción oriental.

Desde el comienzo de este siglo y hasta la década del sesenta se produce una tercera etapa en la asimilación de nuestro territorio y por tanto en la modificación de nuestros paisajes caracterizada por un incremento en la explotación agrícola y ganadera, el desarrollo de la minería de forma intensa localmente, el crecimiento acelerado de las ciudades y un sostenido, aunque incipiente desarrollo industrial especialmente ligado al auge de la industria azucarera, crecimiento de la infraestructura vial y de servicios, etc. Como resultado de esto se acentúa la explotación irracional de los recursos naturales y se produce una intensa modificación en áreas hasta ese momento poco utilizados principalmente de las regiones oriental y central (Iñiguez, L. 1983).

Como resultado de esta prolongada utilización de tierras para las actividades agropecuarias con prácticas agrícolas inadecuadas en muchos casos, la devastación de los bosques y la caótica distribución territorial de las actividades productivas y los asentamientos humanos, más del $80 \%$ del archipiélago cubano presenta fuertes modificaciones de sus paisajes, apareciendo sólo en estado natural y seminatural algunas áreas litorales y las pequeñas islas que rodean a Cuba, así como territorios montañosos pocos accesibles, áres kársticas y ciénagas con poca o ninguna cobertura de suelos (Iñiguez, L., 1983). Véase Figura 4. 


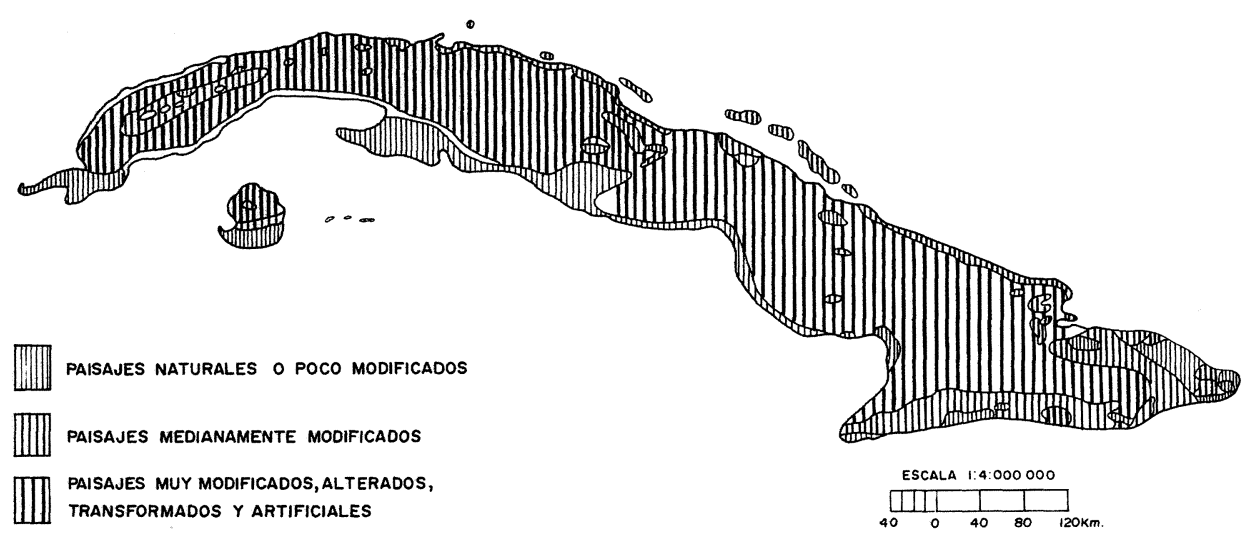

FiguRA 4.-Modificación de los paisajes de Cuba (según Íñigez, L. 1983).

La historia de las modificaciones humanas de las últimas décadas está aún por escribir y, aunque continuó e incluso se incrementó la asimilación de los territorios para el uso agropecuario y las explotaciones mineras, se ampliaron y crecieron las ciudades y se produjo una mayor concentración de la población con sus consecuentes problemas medio ambientales, se tomaron una serie de medidas que han culminado con la creación en 1995 del Centro Nacional de Áreas Protegidas que junto a otras 11 instituciones del recién creado Ministerio de Ciencia, Tecnología y Medio Ambiente están responsabilizadas con la política ambiental de nuestro país.

Los territorios bajo diferentes regímenes de protección totalizaron a finales de 1994, 1.331.900 ha, es decir, cerca del $20 \%$ de la superficie terrestre y plataforma submarina, divididas en más de 300 áreas, que protegen el $96,4 \%$ de las especies vegetales y 321 de las 326 especies de vertebrados del archipiélago.

\section{BIBLIOGRAFIA}

Acevedo, M. (1982): Geografía Física de Cuba, Edit. Pueblo y Educación, vol. I, La Habana, $313 \mathrm{pp}$.

BAUME, O.; BASTIÁ, O., y RODER, M. (1994): «Desarrollo y Estado de las Investigaciones Geográficas del Paisaje en Cuba», Petermanns Geographische Mitt, 138-4, pp. 235-244 (en alemán). 
Borhidi, A. (1991): Phytogeography and Vegetation Ecology of Cuba, Akadémiai Kiadó, Budapest, $858 \mathrm{pp}$.

-, y MuÑIz, O. (1985): Mapa de la Vegetación Potencial de Cuba. Ed. Juceplan, La Habana, 45 pp.

Capote, R., y BerazAn, R. (1984): «Clasificación de las Formaciones Vegetales de Cuba», Revista del Jardín Botánico Nacional, vol. V, núm. 2, pp. 27-75.

-; Berazain, y Leyva, A. (1992): «Flora y Vegetación», en Hammer, K.; Esquivel, M., y Knüpfer, H. (eds.), Origin, Evolution and Diversity of Cuban Plant Genetic Resources, vol. I, pp. 26-36. Institut fur Pflanzengenetik und Kulturpflanzenforschung, Gatersleben, Alemania.

GonzÁlez, E., y LoRA, B. (1985): «Régimen de Lluvia de la Pluvisilva submontana en Cuba», Voluntad Hidráulica, núm. 24, pp. 64-68, La Habana.

Govorchin, R. (1995): «Historia Natural de Cuba» en la Lacsa's World. La Revista Aérea Oficial de Lacsa Costa Rica, pp. 35-51.

Guerra, R. (1971): Manual de Historia de Cuba. Edit. de Ciencias Sociales, La Habana, $720 \mathrm{pp}$.

INSTITUTO DE GEOGRAFIA E INSTITUTO CUBANO DE GEODESIA Y CARTOGRAFIA (1989): Nuevo Atlas Nacional de Cuba, Edit. Inst. Geográfico Nacional de España, Madrid (sin páginas).

IÑIGUEZ, L. (1983): Aspectos geográficos de la protección de la naturaleza en Cuba. Tesis de Doctorado, Universidad de La Habana, $120 \mathrm{pp}$. (inédito).

-, y Mateo, J. (1980). Geografía Física de Cuba. Componentes naturales y paisajes geográficos, Ministerio de Educación Superior, La Habana, 258 pp.

Lecha, L., y Florido, A. (1989): Principales caracteristicas climáticas del régimen térmico del archipiélago cubano. Edic. Academia, La Habana, 56 pp.

MAteo, J. (1988): «Regularidades de la Diferenciación Natural de Cuba», en Ed. Salinas y A. Avella (eds.). Transformación del Medio Geográfico en Cuba. Taller Internacional, pp. 14-39. Univ. de La Habana.

- (1991): Geoecología de los paisajes, Universidad de los Andes, Mérida, Venezuela, 222 pp.

-; Salinas, E., y Guzmán, J. L. (1985): El análisis de los paisajes como fundamento para la planificación de los territorios, Inst. de Planif. Física, JUCEPLAN, La Habana, 18 pp.

-, J.; Iñiguez, L; Salinas, E.; Bollo, M., y Claro, A. (1989): Mapa de paisajes de Cuba a escala 1:1000.000 y nota explicativa, Edic. Inst. Nacional Geográfico de España, Madrid.

NC 93-06-101 (1987): Paisaje. Términos y definciones. Sistema de normas para la protección del medio ambiente. Com. Estatal de Normalización, La Habana, $15 \mathrm{pp}$.

Núñez Jiménez, A. (1972): Geografía de Cuba, Edit. Pueblo y Educación, 4 vols., La Habana, $719 \mathrm{pp}$.

- (1982): Cuba, la naturaleza y el hombre, El Archipiélago, Edit. Letras Cubanas, La Habana. 641 pp.

Pérez DE LA Riva, J. (1977): ¿Cuántos africanos fueron traidos a Cuba? Edit. Ciencias Sociales. La Habana, 31 pp.

Richling, A., y Mateo, J. (1991): «Utilización de los métodos físicos-geográficos complejos en las investigaciones de Cuba y Polonia», Actas Latinoamericanas de Varsovia, 9, pp. 21-44.

Rivero DE LA CALle, M. (1992): Cuba: «A Mosaic of Races and Cultures», en Hammer, K.; M. Esquivel y H. Knüpfer (eds.), Origin, Evolution and Diversity of Cuban Plant Genetic Resources, vol. I, pp. 37-45. Institut fur pflanzengenetik und Kulturpflanzenforschung, Gatersleben, Alemania. 
SAlinas, Ed. (1989): «Paisajes de la Faja Tropical», Geografía Física de los Continentes, II Parte, pp. 201-477; Universidad de La Habana.

- (1991): Análisis y evaluación de los paisajes en la planificación regional en Cuba, tesis de doctorado, Universidad de La Habana, $187 \mathrm{pp}$. (inédito).

- (1995): «Geoecological Organization of the laudecapes as a basic for Regional Planning en Cuba», Proceedings of the 4th Natural Workshop of CSLEM, pp. 37-44. Quebec, Canadá.

-, y otros (1991): «Regional and local levels of cuban landscapes researches». Presentado en World Congress of IALE, Ottawa, Canadá (inédito), 14 pp.

Salinas, Er., y SAlinas, E. (1992): «Features of the nature and landscapes», en Hammer, K., M. Esquivel y H. Knüpfer (eds.), Origen, Evolution and Diversity of Cuban Plant Genetic Resources, vol. I, pp. 12-25. Institut fur pflanzengenetik und kulturpflanzenforschung, Gatersleben, Alemania.

Salinas, Ed.; Mateo, J.; Salinas, Er., y Machado, R. (1993): «Estudios geográficos y clasificación de los paisajes de Cuba en Latinoamerica», Territorios y paises en el umbral del siglo XXI. I Congreso Nacional de Geografía sobre Latinoamerica, pp. 401-411. Edit. Mapfre America, Barcelona.

Salinas, Er., y Salinas, Ed. (1995): «Los paisajes insulares tropicales como destino turístico», Revista Insular, MAB París (en prensa).

Santana, E. (1991): «Nature conservation and sustainable development in Cuba», Conservation Biology, 5: 13-16.

TABIo, E., y Rey, E. (1979). Prehistoria de Cuba, 2da. Edición, Edit. de Ciencias Sociales, La Habana, 234 pp.

ReSUmen: La situación geográfica del archipiélago cubano en el borde suroccidental del anticiclón subtropical del Atlántico Norte, junto a su compleja evolución geólogo-geomorfológica y su carácter insular se constituyen en los factores naturales determinantes de su gran bio y geodiversidad; a lo que se ha impuesto una asimilación socio-económica del territorio particularmente intensa, anárquica e irracional en los últimos cuatro siglos, con una total despreocupación por nuestros valores y recursos naturales.

Palabras Claves: Cuba Insularidad. Evolución geólogo-geomorfológica. Biodiversidad. Paisaje. Modificación humana. 